\title{
OS CURSOS DE PEDAGOGIA E A FORMAÇÃO DAS (OS) PROFESSORAS (ES) PARA A PRÁTICA DOCENTE NA CRECHE: REALIDADE E DESAFIOS
}

\author{
Juliana Lima da Silva* \\ Patricia Maria Reis Cestaro**
}

\begin{abstract}
Resumo: Este texto é constituído por uma discussão teórica construída em duas pesquisas, de mestrado e doutorado, desenvolvidas no Programa de Pós-Graduação em Educação da UFJF. Os estudos objetivam compreender a formação de professoras (es) da Educação Infantil, especialmente da creche, em cursos de Pedagogia. A partir do diálogo com vários autores, é possível compreender o contexto e os desafios da formação docente, além de identificar a invisibilidade da creche nos cursos que formam os seus profissionais. Algumas mudanças vem acontecendo, mas isso ainda não é suficiente. É imprescindível que os cursos de Pedagogia reconheçam a creche como parte integrante da educação básica e contemple conhecimentos referentes ao cotidiano e especificidades da prática docente desenvolvida junto aos bebês e crianças pequenas.
\end{abstract}

Palavras-chave: Formação de professoras (es). Cursos de Pedagogia. Creche.

Introdução

No Brasil, a Educação Infantil vem se consolidando como campo de conhecimento, de pesquisas e de políticas públicas, fundamentalmente, a partir da promulgação da Constituição Federal de 1988, sendo reafirmada pela Lei de Diretrizes e Bases da Educação Nacional - LDB/96, que Ihe confere avanços ao integrá-la à educação básica, prevendo o atendimento das crianças em creche ( 0 a 3 anos de idade) e pré-escola ( 4 e 5 anos).

Essa conquista legal fez com que a criança fosse oficialmente reconhecida como um sujeito de direitos, apesar de ainda não ser concretizado efetivamente no plano social, já que grande parte da população com essa faixa etária não está incluída no sistema educacional por falta de vaga, principalmente os bebês e crianças e pequenas. Como observa Campos (2011, p. 27)

O divórcio entre a legislação e a realidade, no Brasil, não é de hoje. Nossa tradição cultural e política sempre foi marcada por essa distância e, até mesmo, pela posição entre aquilo que gostamos de colocar no papel e o que de fato fazemos na realidade.

\footnotetext{
* Mestranda em Educação, Programa de Pós-Graduação em Educação/UFJF - bolsista Capes, julianalima.silva@yahoo.com.br

** Doutoranda em Educação, Programa de Pós-Graduação em Educação/UFJF, patriciamrcestaro@gmail.com
} 
A vaga em uma creche pública no país tem se tornado coisa rara. Quando conseguem entrar, muitas crianças percebem as creches como espaços fundamentais em suas vidas. As mães sentem-se privilegiadas pela conquista de uma vaga e assumem como a principal preocupação os cuidados referentes à alimentação, higiene e administração de medicamentos. $O$ aspecto pedagógico fica em último plano. Conforme pontua Santos (2014), essa tendência brasileira demarca a ideia de favor e não de direito à educação.

Vale ressaltar que a trajetória da educação de crianças no Brasil é marcada inicialmente por ações caritativas e filantrópicas, pautadas em fins assistenciais e, posteriormente, voltadas para uma perspectiva "educacional", cujo objetivo principal era preparar a criança para obter sucesso no processo de escolarização. Constituiu-se, portanto, um atendimento à criança pequena, associado exclusivamente ao combate à pobreza, à compensação das carências das crianças das camadas populares, à diminuição da mortalidade infantil e à necessidade de liberar a mulher para o trabalho. Tal atendimento resultou em dois tipos de instituições: creches e pré-escolas, as quais tiveram orientações de diferentes esferas administrativas. Nesse sentido e contexto a creche vinculou-se aos setores assistenciais, tendo como foco de trabalho as crianças das camadas populares. Já a préescola, por sua vez, destinou-se, inicialmente, às crianças oriundas das famílias das elites (VIEIRA, 1999; KULMANN JR, 1998).

A valorização da creche e a superação do estigma social associado a esse tipo de atendimento, até então visto como um "mal menor" para famílias e mães consideradas sem condições de educar seus filhos pequenos, vão ocorrer a partir do final da década de 1970, sob a influência do movimento feminista, no contexto dos movimentos sociais urbanos. A princípio, a creche era defendida como um direito das mulheres trabalhadoras; mais tarde, as organizações sociais democráticas passam a se preocupar com a qualidade do atendimento, trazendo o foco para a criança (CAMPOS, 2013).

Foi por meio da articulação desses movimentos sociais, que lutavam pelos direitos humanos de crianças e adolescentes, que conseguimos garantir na Constituição Federal de 1988 a inclusão da creche ao sistema educacional, juntamente com a pré-escola, propondo a educação da criança de 0 a 6 anos como parte integrante da educação básica. A LDB/96 reafirmou essa configuração e introduziu a meta da formação de professores no nível superior para creches e pré-escolas.

Em que pese o fato de as crianças pequenas terem ganhado visibilidade no contexto das políticas públicas, é preciso clareza em relação à educação que se pretende para elas, pois ao tratar da educação infantil, lida-se com pontos muito nevrálgicos, ainda mais arraigados nas creches, tais como: a falta de vagas para milhares de crianças brasileiras; a necessária formação e valorização dos profissionais que atuam nas creches; as condições materiais; o arranjo espaço-temporal adequado, a 
necessidade de discutir as concepções de infância, educação e projeto pedagógico (ou a inexistência dele) que alicerçam o saber/fazer das instituições, dentre outros (SANTOS, 2014).

A LDB/96 demarca a necessidade da formação inicial (art. 62) e da formação continuada (art. 67) para os professores de todas as etapas educacionais. A função de educar e cuidar, de modo integral, exige uma formação específica do profissional que atua nesse segmento. Entretanto, de acordo com Santos (2014), faz-se necessário refletir sobre a maneira como se dá essa formação, para evitar a alienação e a automatização. É preciso (re)significar conceitos e concepções para atender as crianças em seus direitos básicos, bem como refletir sobre quais saberes serão eleitos ou devem ser privilegiados na formação inicial desses profissionais, além de selecionar quais saberes possibilitam a construção de práticas que priorizam a criança e suas experiências. E o que dizer das práticas com os bebês? A questão é como garantir que tais indagações possam, de fato, significar qualidade no atendimento às crianças pequenas na educação infantil. $E$ isso tem a ver com as discussões sobre a reforma curricular dos cursos que formam as (os) professoras (es) nas Universidades (GATTI, BARRETO e ANDRE, 2011; GATTI E NUNES, 2009; DOURADO, 2013).

Segundo Gatti, Barreto e Nunes (2011), as perspectivas de políticas para formação de docentes discutidas em vários fóruns, tais como: Associação Nacional pela Formação dos profissionais da Educação (ANFOPE), Associação Nacional de Pós-Graduação e pesquisa em Educação (ANPED), Centro de Estudos Educação e Sociedade (CEDES), assim como os princípios explicitados nos documentos do CNE (BRASIL. MEC. CNE, 2002, 2006), entre outros, não estão encontrando respaldo nas propostas curriculares da maioria dos cursos de formação de professores. A relação teoria-prática, tão ressaltada em documentos e normas, bem como a integração da concepção curricular, não vem se concretizando no contexto das diferentes licenciaturas.

Para Gatti, Barreto e André (2011), faz-se necessário repensar urgentemente as políticas referentes à formação inicial dos docentes brasileiros, no que tange às instituições formadoras e aos currículos. O estudo de Gatti e Nunes (2009) buscou analisar as propostas curriculares de disciplinas formadoras das Instituições de Ensino Superior nas licenciaturas presenciais em Pedagogia, Língua Portuguesa, Matemática e Ciências Biológicas. Em relação à formação de professores que irão atuar nos anos iniciais da educação básica, realizada nas licenciaturas em Pedagogia, constatou-se a fragmentação do currículo, e um conjunto disciplinar bastante disperso. Nas análises das ementas das disciplinas, verificou-se o predomínio dos referenciais teóricos de natureza sociológica, psicológica ou outros nas disciplinas de formação profissional, com pouca associação com as práticas educacionais. Poucos cursos, segundo as referidas autoras, propõem disciplinas que possibilitem um aprofundamento no campo da educação infantil, sem falar que o aspecto metodológico do trabalho com crianças é pouco referido. O que dizer então do saber/fazer dos futuros docentes que irão atuar com crianças de 0 a 3 anos? 
A autonomia dos entes federados, na elaboração e na implementação de leis em nível local, e das universidades, na formulação de cursos de formação de professores, impacta diretamente o trabalho cotidiano nas creches e escolas de todo o país.

Assim como o trabalho do professor precisa ser repensado, do mesmo modo temos também que repensar a sua formação, uma vez que precisa abarcar os novos desafios que the apresentam, dentre os quais podemos citar: a consideração pelas especificidades dos diferentes níveis e modalidades da educação; o conhecimento das características de desenvolvimento do educando, assim como as dinâmicas culturais e sociais mais amplas. Tais questões precisam ser inseridas no escopo das concepções e diretrizes que devem balizar o processo de formação dos profissionais, levando em consideração as questões curriculares e seus desdobramentos didáticos e-pedagógicos, aliando-os às relações sociais mais amplas (DOURADO, 2013).

Refletir sobre essas discussões da formação docente traz implicações para a melhoria do atendimento às crianças e revela-se, assim, como um campo importante de investigação.

As conquistas legais e suas complexidades conferidas à Educação Infantil e ao processo de formação docente nessa área anunciam um profícuo campo de estudos e pesquisas. Nessa perspectiva, vem aguçando o nosso interesse em compreender como estão sendo delineadas as estruturas curriculares dos cursos presenciais de Pedagogia do município de Juiz de Fora, com foco na educação de bebês e crianças pequenas ( 0 a 3 anos de idade).

Ressaltamos que o Curso de Pedagogia destina-se à formação de professores para exercer funções de magistério na Educação Infantil e nos anos iniciais do ensino fundamental, nos cursos de ensino médio, na modalidade normal, de educação profissional, na área de serviços e apoio escolar e em outras áreas nas quais sejam previstos conhecimentos pedagógicos. O seu campo de atuação engloba, ainda, a gestão educacional, concebida numa perspectiva democrática, conforme estabelece as Diretrizes Curriculares Nacionais do Curso de Pedagogia (BRASIL, 2006).

Para identificarmos essa formação da (o) professor (a) que atua/atuará no contexto da creche, elegemos alguns autores para dialogarmos no decorrer desse texto. Deste modo, faz-se fundamental iniciarmos essa discussão abordando os aspectos históricos e legais que dizem respeito a essa formação e depois sobre as necessidades formativas para a prática educativa da professora de creche.

\section{O contexto da formação docente no Brasil}

A melhoria da qualidade da educação brasileira e questões voltadas para a valorização e formação dos (as) profissionais são debates muito presentes no cenário atual brasileiro. Nesse contexto de desafios referentes a qualidade do ensino, a formação de professores constitui uma das 
questões mais controvertidas e de maior visibilidade, já que os professores e as instituições formadoras são apontados como vilões pelas autoridades educacionais e por diversas modalidades de intelectuais influentes na mídia. Para Saviani (2014), no entanto, ainda que esse aspecto assuma, no Brasil, uma particular gravidade, de modo geral, na atualidade, vem afetando todos os países, em maior ou menor intensidade.

A partir de dados históricos contextualizados por Saviani (2014), pode-se revelar, ao longo dos últimos dois séculos, um quadro de descontinuidade no processo de formação docente no Brasil. A questão pedagógica, de início invisível, foi ocupando lentamente, uma posição de destaque nos ensaios de reformas da década de 1930, porém sem um encaminhamento satisfatório até os dias atuais.

Gatti (2010) menciona que até 1996, as escolas normais é que assumiam a responsabilidade de promover a formação docente para os anos iniciais do ensino fundamental e Educação Infantil. A partir da LDB/96, postula-se a formação de professores em nível superior, estabelecendo um prazo de 10 anos para esse ajuste. Em 2002, as Diretrizes Curriculares Nacionais para a formação de professores são promulgadas e somente em 2006, depois de muitos debates, o Conselho Nacional de Educação aprovou a Resolução n. 1, de 15/05/2006 que institui as Diretrizes Curriculares Nacionais para o curso de Pedagogia (BRASIL, 2006). Com essa legislação, a licenciatura de Pedagogia passa a assumir várias atribuições, embora tenha como foco a formação de professores para os anos iniciais da escolarização. Segundo Gatti (2010), com as orientações dessa legislação, o curso de Pedagogia apresenta-se com uma grande complexidade curricular, além do aspecto de dispersão das disciplinas devido ao tempo de duração do curso e carga horária, tendo em vista que ele deverá promover "a aplicação ao campo da educação, de contribuições, entre outras, de conhecimentos como o filosófico, o histórico, o antropológico, o ambiental-ecológico, o psicológico, o linguístico, o sociológico, o político, o econômico, o cultural” (art. 2ำ, parágrafo 2ํㅡ, inciso II); incluir a formação de habilidades de "planejamento, execução, coordenação, acompanhamento e avaliação de tarefas próprias do setor da Educação, de projetos e experiências educativas não- escolares; a produção e difusão do conhecimento científico-tecnológico do campo educacional, em contextos escolares e não-escolares" (Art. 4으, Parágrafo único, incisos II e III). O egresso em Pedagogia deverá ainda estar apto no que é estabelecido em dezesseis incisos do Artigo 50 desse mesmo texto legal, além do cumprimento do estágio curricular de acordo com o disposto no inciso IV, do Artigo 8‥ Essas determinações criaram dificuldades para o desenvolvimento curricular desses cursos, ainda não bem avaliadas. Gatti (2010, p. 1358) pontua que: "enfeixar todas essas orientações em uma matriz curricular, especialmente para as classes noturnas onde se encontra a maioria dos alunos desses cursos, não é tarefa fácil" 
Também Saviani (2014) relata que no Brasil, o que temos encontrado é a precariedade das políticas formativas, cujas sucessivas mudanças não estabeleceram ainda um padrão mínimo e consistente de preparação docente frente aos desafios da educação escolar do nosso país. Segundo Saviani (2014), tal fato pode ser constatado pela estrutura organizativa da formação docente brasileira, fundamentada, de maneira geral, pelas diretrizes curriculares nacionais para a formação de professores da educação básica (Parecer CNE/CP n. 9/2001; Resolução CNE/CP n. 1/2002) , Diretrizes Curriculares Nacionais para o Curso de Pedagogia (Parecer CNE/CP n. 5/2005; Resolução CNE/CP n. 1/2006) e iniciativa do MEC de organizar o sistema nacional de formação dos profissionais do magistério, por meio da coordenação de Aperfeiçoamento de Pessoal de Nível Superior (CAPES) e educação a distância, com a Universidade Aberta do Brasil (UAB). Para o autor, uma breve análise desses documentos legais nos alerta sobre os dilemas aqui concentrados.

Dentre os principais, o pesquisador destaca: Diagnóstico relativamente adequado, porém incapaz de encaminhar soluções satisfatórias; Textos dos pareceres e Diretrizes excessivos no acessório e muito restritos no essencial; Centralidade da noção de "competências" versus incapacidade de superar a incompetência formativa; formação do professor técnico versus formação do professor culto, mediante a redução de investimento; Dicotomia entre os dois modelos básicos de formação de professores (modelo cultural-cognitivo e modelo pedagógico-didático) (SAVIANI, 2014, p. 67-70).

A partir de desafios que caracterizam a política de formação docente no Brasil atualmente, Saviani (2014) sugere algumas possibilidades. Vejamos o quadro a seguir:

\begin{tabular}{|c|c|}
\hline Desafios & Possibilidades \\
\hline $\begin{array}{l}\text { 1. Iniciativas fragmentadas e dispersas- } \\
\text { Diversificação de modelos de } \\
\text { organização da educação superior }\end{array}$ & $\begin{array}{l}\text { Proposta de organicidade na formação de } \\
\text { professores baseada no modelo universitário } \\
\text { e nas faculdades de educação caracterizada } \\
\text { como lócus privilegiado da formação } \\
\text { docente. }\end{array}$ \\
\hline $\begin{array}{l}\text { 2. Falta de continuidade das políticas } \\
\text { educacionais }\end{array}$ & $\begin{array}{l}\text { Política educacional de longo prazo que dê } \\
\text { prioridade para a formação de professores } \\
\text { cultos em cursos de longa duração. }\end{array}$ \\
\hline $\begin{array}{l}\text { 3. Organização burocrática e } \\
\text { funcionamento dos cursos }\end{array}$ & $\begin{array}{l}\text { Tornar as Faculdades de Educação espaços de } \\
\text { ensino e pesquisa, em ambientes de intenso } \\
\text { e exigente estímulo intelectual aos } \\
\text { candidatos ao magistério. }\end{array}$ \\
\hline
\end{tabular}




\begin{tabular}{|c|c|c|}
\hline & $\begin{array}{l}\text { Separação entre as instituições } \\
\text { formativas e o funcionamento das } \\
\text { escolas. }\end{array}$ & $\begin{array}{l}\text { Proposta de fortalecimento entre os cursos } \\
\text { de formação e o funcionamento das escolas. } \\
\text { Tomar como ponto de partida o modo de } \\
\text { funcionamento das escolas para a } \\
\text { organização do processo formativo e } \\
\text { redimensionar os estágios como instrumento } \\
\text { de colaboração conjunta na formação dos } \\
\text { novos professores. }\end{array}$ \\
\hline 5. & $\begin{array}{l}\text { Paradoxo pedagógico expresso na } \\
\text { contraposição entre teoria e prática, } \\
\text { conteúdo e forma, conhecimento } \\
\text { disciplinar e saber pedagógico- } \\
\text { didático. }\end{array}$ & $\begin{array}{l}\text { Proposta de formulação teórica que supere } \\
\text { as oposições excludentes e ponha em cena a } \\
\text { articulação teoria-prática, conteúdo e forma, } \\
\text { professor e aluno, movimento do trabalho } \\
\text { pedagógico. }\end{array}$ \\
\hline 6. & $\begin{array}{l}\text { Carga horária precária de trabalho e } \\
\text { salários baixos. }\end{array}$ & $\begin{array}{l}\text { Medidas de valorização do professor: jornada } \\
\text { de trabalho de tempo integral em uma escola } \\
\text { única, com inclusão de tempo para } \\
\text { preparação das aulas, orientação de estudos } \\
\text { dos alunos, participação na gestão da escola, } \\
\text { reuniões de colegiados e atendimento a } \\
\text { comunidade; Salários dignos; Valorização } \\
\text { social da profissão docente. Atrair candidatos } \\
\text { dispostos a investir tempo e recursos numa } \\
\text { formação de longa duração. }\end{array}$ \\
\hline
\end{tabular}

Quadro 1 - Desafios e possibilidades para as políticas de formação docente. Fonte: produzido pelas autoras.

O diálogo com Saviani (2014), possibilita-nos compreender que há uma intrínseca relação entre a formação de professores e o exercício do trabalho docente. Nesse contexto, não se pode solucionar o problema da formação de professores sem enfrentar as condições reais do magistério. Tal fato revela a articulação e a relação entre esses dois aspectos na forma de ação recíproca.

Nessa perspectiva, pode-se atribuir a qualidade ou não do trabalho docente associada à formação do professor e vice-versa. Isso pode se dar em vários sentidos. Num primeiro sentido, é necessário entender que a formação de professores se constitui como um trabalho docente, se pensarmos nos formadores desse processo. Se as políticas educativas, de modo geral, não priorizam condições adequadas para o desenvolvimento do trabalho docente, também os cursos de formação de professores terão condições inadequadas, o que acarretará uma formação também inadequada. 
Num segundo sentido, verifica-se a influência das condições de trabalho docente das escolas no processo de formação dos sujeitos que realizam os estágios. Se o funcionamento das escolas é precário, os estágios também se configurarão precários e, no limite, podem ser até mesmo, inviabilizados ou reduzidos a procedimentos meramente formais.

Outro ponto que merece destaque refere-se ao impacto decisivo das condições de trabalho docente no processo de formação do professor no que diz respeito a ligação direta ao valor social da profissão. Se as condições de trabalho docente são precárias, ou seja, se o ensino realiza-se em situação difícil e com remuneração pouco compensadora, os jovens não investirão tempo e recursos numa formação mais exigente e de longa duração. Em consequência, os alunos dos cursos de formação de professores serão desestimulados e pouco empenhados, o que refletirá o seu desempenho em aspecto negativo.

Por fim e sem dúvidas, a necessidade do provimento de recursos financeiros é o principal desafio a ser enfrentado para garantir uma formação consistente e assegurar condições adequadas de trabalho.

2. A educação de bebês e crianças pequenas na formação dos professores nos cursos de Pedagogia

Como já mencionado, é a partir da promulgação e estabelecimento de alguns documentos legais que a Educação Infantil passa a ser reconhecida como a primeira etapa da educação básica e as crianças começam a ganhar visibilidade nas discussões e implementações de políticas públicas. Assim como afirma Kramer (2006), no contexto brasileiro a partir dos fóruns e outros movimentos, aumenta o número de debates e discussões que buscam garantir este direito a partir das políticas de educação infantil, práticas com as crianças e as alternativas de formação.

No entanto, mesmo com muitos avanços, o reconhecimento e valorização da prática dos professores que atuam especificamente nas creches ainda são pouco valorizadas e reconhecidas nos cursos de formação inicial, especificamente o de Pedagogia.

Para Kramer (2006), a formação para o trabalho com crianças pequenas ainda é algo novo no contexto das escolas brasileiras. Ainda desconhecido por muitos e visto como um trabalho menos nobre.

Uma desvalorização histórica, presente desde a origem das instituições de atendimento aos bebês e crianças pequenas. Dessa forma, muitos ainda veem a garantia do espaço da Educação Infantil na formação de professores, como desvalorização do curso de Pedagogia. Kramer (2006) destaca que esta diferenciação dos níveis de ensino se materializa na realidade de vários municípios 
que pagam um salário inferior aos docentes que atuam com crianças pequenas, não considerando sua escolaridade mas sim o tamanho e idade de seus alunos.

Portanto, é preciso considerar que definir o referido curso como o lugar de formação de professores da Educação Infantil ainda não é solução, mas o coloca em destaque. É o início de um longo caminho, já que muitas questões curriculares ainda precisam ser enfrentadas. (KRAMER, 2006, p. 808) Segundo a autora, nas próprias universidades é grande o número de pedagogos que lá estão e que não sabem lidar com as crianças e os muitos outros que ainda não reconhecem o que a pedagogia tem a ver com o corpo, bebês e fraldas, por exemplo.

Para Kramer (2006), em uma realidade em que muitos profissionais ainda atuam sem formação em nível superior ou médio, colocar o curso de Pedagogia como o lócus desta formação já é um grande avanço.

Mas por que a problematização e preocupação com a formação dos profissionais desta faixa etária? Para trabalhar com bebês e crianças pequenas ter afeto e jeito não bastam? A resposta é não. A realidade da creche reconhecida como um espaço de cuidado e educação não permite mais a atuação de profissionais sem uma formação adequada. O que é estabelecido também em documentos aqui já mencionados como a LDB/96 e as Diretrizes Curriculares para os Cursos de Pedagogia (2006). No primeiro, em seu artigo 62 estabelece-se que o(a) professor(a) tenha concluído ao menos o ensino médio, na modalidade Normal, sendo considerada mais apropriada a formação em nível superior. Por sua vez, as Diretrizes de 2006 afirmam o curso de Pedagogia como o lócus da formação docente para exercer funções de magistério na Educação Infantil.

Diversas são as especificidades inerentes à prática pedagógica com bebês e crianças de 0 a 3 anos. Por isso, é necessário que seja oferecida nos cursos de Pedagogia uma formação que subsidie e oriente os estudantes, mesmo que minimamente, para a compreensão de sua futura profissão nos diversos níveis de ensino e nas atribuições para os quais são habilitados, e isto não deve ser diferente para a prática na creche.

Sobre as especificidades do trabalho com esta faixa etária, Barbosa (2010) nos aponta alguns aspectos: a instituição de Educação Infantil é um espaço em que educação e cuidado devem ser indissociáveis e estas funções devem ser compartilhadas com as famílias. Outro é a necessidade de novas experiências no cotidiano das crianças já que elas não vivenciam os currículos somente através de atividades dirigidas, mas também, e principalmente, através de vivências, experiências e interações com pessoas e objetos, possibilitando desta forma, o desenvolvimento de suas linguagens verbais, gestuais, musicais, dentre outras, assim como o progresso de suas formas específicas de se comunicar e expressar. Por isso também é preciso valorizar a importância das brincadeiras e das interações sociais. 
As professoras precisam estar sensíveis às vozes e expressões das crianças e proporcioná-las uma vivência compartilhada. Valorizar as relações e interações entre os bebês e crianças também se faz importante. Neste caso, a ação pedagógica precisa proporcionar o encontro entre elas em diferentes momentos e espaços, favorecendo o desenvolvimento afetivo, corporal e cognitivo.

A organização do espaço é fundamental também para favorecer as relações, interações e brincadeiras.

O tempo é outra especificidade. Os bebês, por exemplo, precisam de mais tempo para comer, brincar e dormir, tempos significativos. Como afirma Barbosa (2010, p. 9), na difícil tarefa de conhecer e significar o mundo, os bebês precisam de tempo para interagir, observar e criar. São nestes momentos, com o auxílio de um adulto ou na interação com seus pares que as crianças iniciam a aprendizagem do cuidar de si e dos outros e a se relacionar com o mundo.

Neste sentido, Barbosa (2010) ressalta que ao elaborar uma rotina desde o acolhimento, alimentação, higiene e brincadeiras, as professoras precisam atentar ao que é proposto já que as atividades realizadas proporcionam aos bebês e crianças um certo domínio sobre o mundo em que vivem. Pela repetição dos rituais, geralmente desenvolvidos com as mesmas pessoas, as crianças constroem uma memória que passa a constituir sua identidade social e de grupo. São momentos de encontros, aprendizagem, relações, convivência e cooperação.

Estes aspectos aqui citados são alguns dos tantos que caracterizam mais especificamente a prática pedagógica na creche. O que justifica, mais uma vez, a necessidade de uma formação inicial que contemple a Educação Infantil, a creche e esta faixa etária. No entanto, a partir dos discursos de pesquisadores, estudiosos e profissionais da área não é isto que vem acontecendo.

Kramer (2006) ressalta que a consolidação desta etapa da educação básica envolve muitos aspectos e é necessário discutir investimentos, currículos, concepções de infância, projetos educativos e outros.

Azevedo (2013) reafirma que muitos são os obstáculos frente à formação docente e que não é diferente quando se trata da formação para o trabalho na Educação Infantil. Na grande maioria dos cursos de formação inicial, tanto em nível médio quanto superior, valoriza-se muito mais as práticas e as discussões que se referem ao Ensino Fundamental. Quando fala-se em Educação Infantil, há um enfoque maior na prática com as crianças de quatro e cinco anos, desconsiderando as de até três. (AZEVEDO, 2013, p. 75)

Sobre este aspecto Kiehn (2008) traz também contribuições ao afirmar que a formação do professor de Educação Infantil ainda ocupa uma posição secundarizada, priorizando a docência no Ensino Fundamental. Este lugar demonstra o entendimento e o lugar que a formação de professores para atuação com bebês e crianças pequenas ocupa no meio acadêmico (p. 13). 
Ainda Azevedo (2013) alerta-nos para o fato de que três ou quatro anos em um curso de formação de professores não é o suficiente para que se forme profissionais para a Educação Infantil e para o Ensino Fundamental, abordando as peculiaridades e demandas de cada um destes segmentos. E mais: em nossa realidade, as políticas educacionais ainda priorizam o ensino para as crianças maiores de seis anos. Neste sentido, as especificidades da formação para a Educação Infantil acontecem de forma muito rasa, apenas para cumprir determinações legais.

Em concordância com aquilo já mencionado por Kramer (2006), em que a precariedade na formação do professor de Educação Infantil reflete as ideias e preconceitos trazidos desde a origem das instituições de atendimento às crianças, afirma:

A formação do professor da Educação Infantil foi sempre muito precária ou inexistente. Considerando-a vinculada à origem e à história das instituições de atendimento infantil, pode-se dizer que essa precariedade decorre, também, da classe social a que tal educação se direcionava. (AZEVEDO, 2013, p. 76)

Diante deste contexto, a autora aponta que os professores já graduados e que atuam nas escolas, principalmente na Educação Infantil, manifestam a necessidade de uma formação que contemple conhecimentos relacionados à Educação Infantil, infância e a organização do trabalho pedagógico neste nível. E muitas vezes se mostram sem crítica e autonomia para encaminharem sua prática.

Kiehn (2007) nos atenta ao fato de que os currículos dos cursos de Pedagogia ainda estão muito voltados ao processo de ensino e aprendizagem e suas metodologias e pouco direcionados ao reconhecimento dos protagonistas deste processo que são as crianças. Os assuntos sobre crianças e infâncias são pouco abordados.

Já em seu trabalho em 2009, Kiehn reafirma que os currículos dos cursos de Pedagogia destacam-se pelos fundamentos gerais e tratam pouco dos fundamentos específicos para a prática na Educação Infantil. Segundo a autora, é preciso que haja uma integração teórica que possibilite aos egressos do curso acesso aos conhecimentos que envolvem a constituição deste nível de ensino, assim como "embates e debates oriundos da tentativa de delimitações de papéis, funções, espaços, políticas, somados a defesa da especificidade deste nível de educação." (KIEHN, 2009, p. 10)

Também Azevedo (2013), como tantos outros autores, traz a necessidade de uma formação com mais articulação entre teoria e a realidade vivenciada nas instituições educacionais, que permita ao professor uma prática reflexiva.

A prática do professor não é somente reprodução dos conhecimentos teóricos adquiridos durante a formação, mas é principalmente espaço em que novos saberes são desenvolvidos e produzidos. Nesse contexto, grande parte da formação deveria pautar-se nos saberes produzidos, já que são estes os exigidos no exercício da profissão. Tardif (2010) 
O mesmo autor abordado acima, defende que os saberes dos professores são plurais pois, originam-se dos currículos, das experiências de sua história de vida, da ciência, enfim. E é por isso que os saberes produzidos na prática precisam ser valorizados. Isto não quer dizer que a formação deve incentivar uma reprodução das práticas já existentes, mas que esteja voltada para a realidade das escolas e salas de aulas. O autor aponta que, quando vão para as escolas, os professores recémformados percebem que os conhecimentos disciplinares vistos na universidade não se relacionam com sua ação diária.

Segundo Tardif (2010), os cursos de formação estão cheios de teorias históricas, psicológicas, sociológicas, políticas e vazios daquilo que professores aprendem e produzem todos os dias em suas práticas. Uma não é mais importante que a outra, portanto, estas devem se complementar. Isto possibilita a formação de um profissional reflexivo, capaz de pensar sobre sua ação, reavaliar, modificar e agir. Os estágios mais longos, contato frequente com o ambiente da prática e análise de casos são algumas possibilidades para que de fato, isto aconteça.

\section{Considerações finais}

É preciso reconhecer os avanços alcançados até aqui, mas de fato, a formação de professores de Educação Infantil, principalmente para atuação na creche não é uma tarefa fácil. Muitos são os obstáculos que ainda precisam ser enfrentados, dentre eles o reconhecimento e valorização da Educação Infantil, inclusive a creche com o atendimento de crianças de 0 a 3 anos, como a primeira etapa da educação básica e por isso, merecedora de um olhar cuidadoso assim como os demais níveis de ensino, cada um a seu tempo e com sua importância.

Um fator relevante é a necessidade de desconstrução da visão ultrapassada de creche arraigada na sociedade e também no meio acadêmico. Esta não é mais uma instituição com fins de atendimento apenas às crianças menos favorecidas e nem espaço onde apenas cuidados precisam ser dispensados aos bebês e crianças que ali estão. A creche é lugar de cuidado e educação. É uma instituição que destina-se aos bebês e crianças pequenas de todas as classes sociais, independentemente de cor, raça, religião ou cultura, por exemplo. O que infelizmente não é uma realidade pela falta de vagas.

Reconhecer esta importância é um meio de buscar melhorias na formação das (os) professoras (es) de Educação Infantil para que estejam mais preparados em lidar com a rotina e o cotidiano da creche, suas especificidades, a compreensão de criança e infância sendo possível, desta forma, a realização de um trabalho mais coerente com aquilo que é proposto na LDB, buscando de fato incentivar e contribuir para o desenvolvimento físico, psicológico, afetivo, intelectual, linguístico e social. 
Melhorias na formação dos professores e reconhecimento este que devem possibilitar também mais crescimento em estrutura física e pessoal, aumento no número de vagas disponibilizadas nas creches, valorização do professor tanto em carreira quanto salarial, desenvolvimento e investimento de políticas públicas para este nível de ensino.

\title{
THE PEDAGOGY COURSES AND THE TEACHER'S FORMATION TO TEACHING IN A DAYCARE: REALITIES AND CHALLENGES
}

\begin{abstract}
This paper is a result from the theoretical debate between two researchers from master and PHD studies, developed inside the Postgraduation Program in Education of UFJF. The researches aim to comprehend the preschool teacher formation in Pedagogy courses, especially those who works with a daycare. From the dialogue with some authors, it is possible to comprehend the conditions and the challenges of the teacher's formation courses and also to identify the invisibility of daycare studies inside these courses. Some changes have been happening, but they are not enough. Is essential that Pedagogy courses recognize the daycare as fully part of the basic educational system and contemplate knowledges that is referring to the daily routine and contemplate the teacher's practice developed with babies and small infants.
\end{abstract}

Keywords: Teacher's formation. Pedagogy courses. Daycare.

Referências

AZEVEDO, Heloisa Helena Oliveira. Educação Infantil e formação de professores: para além da separação cuidar-educar. 1ed. São Paulo: Editora Unesp, 2013.

BARBOSA, Maria Carmem. Especificidades da ação pedagógica com os bebês. In: I Seminário Nacional Currículo em Movimento - Perspectivas Atuais, Belo Horizonte, 2010. Anais do I Seminário Nacional Currículo em Movimento-Perspectivas atuais, Belo Horizonte, 2010. Disponível em: <http://portal. mec.gov.br/docman/dezembro-2010-pdf/7154-2-2-artigo-mec-acao-pedagogica bebes-m-carmem/file>. Acesso em: 22 fev. 2017.

BRASIL. Lei no 9.394, de 20 de dezembro de 1996. Lei de Diretrizes e Bases da Educação Nacional. Brasília, 1996. Disponível em: <http://portal.mec.gov.br/arquivos/pdf/ldb.pdf>. Acesso em: 05 set. 2016.

Constituição da República Federativa do Brasil de 1988. Brasília, 1988. Disponível em: <http://www.planalto.gov.br/ccivil_03/constituicao/constituicaocompilado.htm>. Acesso em 02 set. 2016.

. Ministério da Educação. Conselho Nacional de Educação. Resolução CNE/CP no 1 de 18 de fevereiro de 2002. Institui DiretrizesCurriculares Nacionais para a Formação de Professores da Educação Básica,em nível superior, curso de licenciatura, de graduação plena. Portal MEC.Brasília: MEC/CNE/CP 2002. Disponível em: <http://portal.mec.gov.br/cne/arquivos/pdf/rcp01_02.pdf>. 
. Ministério da Educação. Conselho Nacional de Educação. Diretrizes Curriculares Nacionais

para o Curso de Graduação em Pedagogia, licenciatura. Brasília, 2006. Disponível em: <http://portal.mec.gov.br/cne/arquivos/pdf/rcp01_06.pdf>. Acesso em: 02 set. 2016.

CAMPOS, Maria Malta. Entre as políticas de qualidade e a qualidade das práticas. Cadernos de Pesquisa (Fundação Carlos Chagas. Impresso), v. 43, p. 22-43, 2013.

DOURADO, Luiz Fernandes. A formação de professores e a base comum nacional: questões e proposições para o debate. In: RBPAE, v. 29, p. 367-388, mai/ago. 2013.

GATTI, Bernadete Angelina; BARRETO, Elba Siqueira de Sáe ANDRÉ, Marli. Políticas Docentes no Brasil: um estado da arte. Brasília: UNESCO, 2011.

GATTI, Bernadete. Formação de professores no Brasil: características e problemas. In: Educação e Sociedade, Campinas, v. 31, n. 113, p. 1355-1379, out.-dez. 2010. Disponível em: <http://www.cedes.unicamp.br/>. Acesso em: 24 jan. 2017.

GATTI, B. A.; NUNES; M. M. R. (Orgs.). Formação de professores para o ensino fundamental: estudo de currículos das licenciaturas em Pedagogia, Língua Portuguesa, Matemática e Ciências Biológicas. Coleção Textos FCC,n. 29, 2009.

KIEHN, Moema. A concepção de criança e de infância nos currículos de formação de professores da Educação Infantil. In: 30a Reunião Anual da Anped, 2007, Caxambu - MG. Disponível em: <http://30reuniao.anped.org.br/ posteres/GT07-2875--Int.pdf>. Acesso em: 12 jan. 2017.

Tendências e perspectivas na educação da pequena infância: um olhar sobre a formação docente. In: I Seminário de Grupos de Pesquisa sobre Crianças e Infâncias, 2008, Juiz de Fora. Anais do II Seminário de Grupos de Pesquisa sobre Crianças e Infâncias, 2008, Juiz de Fora.

. Educação da pequena infância: um olhar sobre a formação docente. In: 32a Reunião Anual da Anped, 2009, Caxambu - MG. Disponível em: <http://32reuniao.anped.org.br/ arquivos/trabalhos/GT07-5711--Int.pdf>. Acesso em: 07 nov. 2016.

KUHLMANN JR., M. Infância e Educação Infantil: uma abordagem histórica. Porto Alegre: Mediação, 1998.

KRAMER, Sônia. As crianças de 0 a 6 anos nas políticas educacionais no Brasil: Educação Infantil e/é fundamental. Educação e Sociedade, vol. 27, n. 96 - Especial, p. 797-818, out. 2006. Disponível em: <http://www.scielo.br/pdf/es/v27n96/a09v2796.pdf>. Acesso em: 13 jan. 2017.

SANTOS, Nubia Shaper. As ideias fora do lugar e o lugar fora das ideias. In: ARAGÃO, Maria Darcilene (Org.). Trajetórias e Pesquisas em creches e escolas de Educação Infantil. Juiz de Fora, MG: Editora UFJF, 2014.

SAVIANI, Dermeval. O lunar de Sepé Paixão, dilemas e perspectivas na educação. Campinas, SP: Autores Associados, 2014.

TARDIF, Maurice. Saberes Docentes e Formação Profissional. 11ed. Petrópolis: Vozes, 2010.

VIEIRA, L.M.F. A formação do profissional da educação infantil no Brasil no contexto da legislação, das políticas e da realidade do atendimento. In: Pró- posições - vol10,n. 1 (28) mar 1999. 